Article

\title{
Pedagogical Laboratories: A Case Study of Transformative Sustainability Education in an Ecovillage Context
}

\author{
Jason Papenfuss ${ }^{1, *(D)}$ and Eileen Merritt ${ }^{2}$ (D) \\ 1 School of Sustainability, Arizona State University, Tempe, AZ 85287, USA \\ 2 Mary Lou Fulton Teachers College, Arizona State University, Phoenix, AZ 85069, USA \\ * Correspondence: jandl_papenfuss@msn.com; Tel.: +1-612-568-3099
}

Received: 30 May 2019; Accepted: 15 July 2019; Published: 17 July 2019

\begin{abstract}
Students, practitioners, and scholars of sustainability education are increasingly calling for divergent curricula and novel pedagogical approaches that cultivate transformation and emancipation at both the individual and institutional levels. For decades, ecovillages around the globe have provided alternatives for sustainable living and many have also developed alternative educational approaches. For this reason, ecovillages can be important learning laboratories for experimenting with sustainability education curricula and pedagogies, allowing scholars to learn across disciplinary, cultural, and worldview boundaries. In the present study, we conducted a descriptive case study of Findhorn Foundation College's 5-week Ecovillage Design Education course. By applying a narrative analysis of archives, field notes, surveys, and interviews, we arrived at 17 different categorical elements across six major themes. Using the field data, we linked these categorical elements to three consistent pedagogical elements: ritual pedagogies, pedagogies of story, and collaborative pedagogies. We conclude by highlighting several inductive themes present in participant data that indicated potential hindrances, constraints, and cautionary tales regarding implementation of these pedagogies in higher education contexts situated in the Global North.
\end{abstract}

Keywords: transformation; emancipation; ecovillage; pedagogy; sustainability education; higher education

\section{Introduction}

Whether we tend to relate to the concept of sustainability with frustration or with hope, there is little doubt that humanity is approaching what systems scientists refer to as a bifurcation point. A bifurcation point is a "threshold of stability at which the dissipative structure may either break down or break through to one of several new states of order" [1] (p. 191). The dissipative structure referred to here is nothing less than human civilization. This daunting prospect raises urgent questions. What is required of humanity to avoid collapse and pass through the threshold to higher states of organization? How should we prepare?

Unfortunately, envisioning, strategizing, and enacting the necessary large-scale transformations remains largely absent from societal discourse, and even the term "sustainability" itself remains a contested concept. Its ambiguity means that it is often defined by what it is not. Accordingly, descriptions of sustainability often begin with a recital of the many challenges that human civilization faces. Some scholars claim that our inability to reify the concept parallels our inability to adequately address those challenges [2]. However, Wals and Corcoran take a more hopeful approach, arguing that the multiple meanings of sustainability are its strength, and that "the process of giving [it] meaning within a context is meaningful learning" [3-5] (p. 91). For them, meaning making is also crucial to learning and complements meaning receiving from a knowledgeable other. 
Institutions of higher learning (IHLs) are intended to be centers of meaning making and are expected to play a crucial role in a global transition toward sustainability. Therefore, scholars and international bodies are increasingly calling for innovative pedagogies (i.e., methods and practices of teaching) that lead toward transformative [6-8] and emancipatory [8-11] learning, collectively referred to henceforth as transformative sustainability education (TSE). Transformative learning for sustainability engages multiple ways of knowing that include the intellect, affect, body, and intuition. It implies reflexivity into our dominant worldviews and a self-awareness that bends back onto the learner, ultimately leading to lasting changes in perspectives, values, and behavior [4,12]. Emancipatory learning, however, is concerned mainly with the awareness of and engagement with power structures through interpersonal dialogue and action. It is also based on the notion that sustainable change cannot happen without empowering marginalized populations. Thus, TSE differs from previous frameworks in that its theoretical foundations incorporate the work of critical pedagogues like Freire [5] and hooks [13].

Yet, IHLs are typically constrained by political and economic forces that tend to advocate for learning approaches aligned with neoliberal labor specialization and that are either transmissive, instrumental, or both [4,14]. In their articulation of the goal of sustainability education, Sterling et al. explain:

Sustainability education seeks to nurture transformative learning experiences that can heal, empower, energize, and liberate potential for the common good. But. . educational systems or institutions cannot adequately support such transformative education and transformative learning experiences unless they themselves have experienced or are experiencing sufficient transformative processes consistent with this ethos. [15] (p. 324)

Consequently, education in IHLs contradicts sustainability education when institutions remain unwilling to look critically at their goals and practices. IHLs also frequently conform to the epistemological and ontological frameworks of the dominant culture within which they are embedded, making the possibility of exploring new and challenging onto-epistemological domains, a growing trend in TSE $[16,17]$, much less likely. Thus, there is a need for alternative learning contexts and institutions that are relatively free of these constraints and willing to explore divergent curricula, novel pedagogies, and be themselves transformed.

For decades, ecovillages around the world have served as hubs of social experimentation and place-based alternatives for sustainable living $[18,19]$. According to the Global Ecovillage Network (GEN), an ecovillage is defined as an "intentional, traditional or urban community that is consciously designed through locally owned participatory processes in all four dimensions of sustainability (social, culture, ecology and economy) to regenerate social and natural environments" [20]. While they are often conflated with utopian alternatives to mainstream Western society, ecovillages are more appropriately regarded as learning laboratories for social innovation [20,21].

Many ecovillages' attempts to innovate have also taken the form of experimental educational programming within the ecovillage itself [22,23], leading to forms of sustainability education with features distinct from traditional IHLs. For example, education within ecovillages is relatively free of the institutional demands experienced by IHL faculty, making ecovillage course designers more willing to diverge from transmissive and instrumental pedagogies and explore novel onto-epistemological domains. Ecovillage education is also (typically) situated within the ecovillage, addressing the importance of contextualized and experiential learning [6,24,25]. Conversely, IHLs are often situated in communities where sustainable living is not recognized as a social imperative and where sustainability education is therefore more intellectual and less embodied. Lastly, while many are striving to be hubs of social transformation, the metanarrative of most IHLs remains aligned with neoliberal labor specialization $[14,26]$. Ecovillages, however, are explicitly intentional about social transformation; therefore, their educational approaches often align with the themes of transformation and emancipation called for by scholars. 


\section{The Current Study}

Despite international calls to transition toward TSE [27,28], empirical studies that explore pedagogies of transformation and emancipation are still needed [8]. The purpose of the current study was to describe the pedagogical approaches of a course in community-based sustainability education titled "Ecovillage Design Education." The goal of the 5-week annual course was to promote "small sustainable communities based on a holistic worldview with the vision of transformation of self and society" [29] (p. 8). Our research questions were: (1) what are the elements (richly described) of a TSE curriculum for sustainability outside of the traditional IHL? and (2) to what extent is the program transformative and emancipatory, for whom, and in what ways (i.e., which pedagogical practices)? Our overall research goal was to provide TSE practitioners with pedagogical tools of their own and help to corroborate and further develop a growing theoretical literature in TSE.

\section{Methods}

\subsection{Design, Setting, and Unit of Analysis}

This investigation followed a descriptive case study design focused on an exemplary case, where multiple forms of qualitative data were collected at multiple contextual levels [30] (Figure 1). The strategy of collecting data at different levels of embeddedness (e.g., administrators, faculty, and students) was intended to strengthen the findings through convergence and data triangulation [30,31]. The study was conducted at Findhorn Foundation College (henceforth "college"), a non-governmental organization (NGO) located near Forres, Scotland, U.K. The college offers several courses in sustainability education with the explicit goal of providing transformative learning opportunities for participants using approaches that are holistic, collaborative, and systems-oriented [32]. The college is unique in that it is located within the Findhorn Ecovillage, a spiritually- and ecologically-oriented community that was started in the early 1960 s by a small group who were seeking to live lives more aligned with the natural cycles of the surrounding environment. Today, the ecovillage is home to more than 350 residents, as well as approximately 40 social enterprise organizations, and is part of a growing worldwide network of sustainable ecovillages.

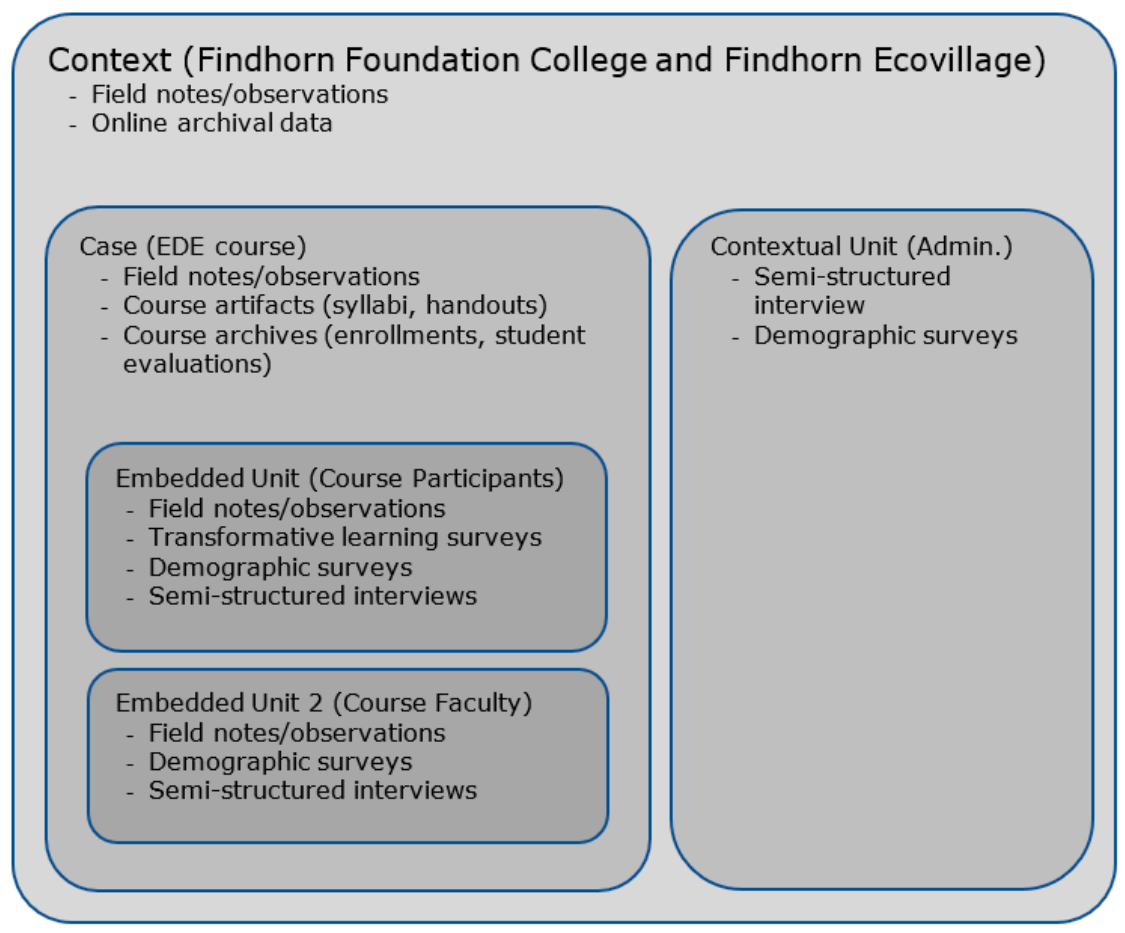

Figure 1. Data collection framework for the embedded case study design [30]. 
The unit of analysis, or the actual "case" in this study [30], was the Ecovillage Design Education (EDE) course, which took place at the college from 2 October-17 November 2018. The EDE is offered annually through a partnership with Gaia Education, a non-governmental organization whose role it is to assist in designing, organizing, and promoting the course. During the 5-weeks, participants of the EDE are typically housed within the ecovillage and take part in many of its daily rhythms. The 2018 EDE had 4 curricular components: the ecological, economic, social, and worldview modules. While the ecological and economic modules articulated sustainability on a material level, the social and worldview components included political and symbolic dimensions respectively. For example, the social module included sub-elements of "Art, Ritual, and Social Transformation; Education and Social Networks; and Activism, and Leadership and Empowerment" [29] (p. 5). These goals overlapped with "Freirean" approaches to social transformation through emancipatory learning [5]. The worldview module included sub-elements of "Reconnecting with Nature, Socially Engaged Spirituality, and Transformation of Consciousness" [29] (p. 5). Consequently, it was aligned with the extra-rational threads of transformative learning theory that emanate from Boyd [33] and Daloz [34]. For these reasons, the 2018 EDE offered an exemplary case for describing the processes and outcomes of TSE outside of a typical higher education setting.

\subsection{Study Participants}

Nine EDE students ( 7 females, 2 males), two faculty ( 1 female, 1 male), and two administrators (both female) elected to participate in this study. Students ranged in age from 20 to 76 years old $($ mean $=46.4$, standard deviation $=19.0)$, while faculty and administrators ranged from 40 to 77 years old (mean $=61.6$, standard deviation $=15.8)$. Students' origins were diverse and included Latvia, Germany, Switzerland, Denmark, Brazil, Norway, and the United States. Participant sampling for this study was voluntary and students that consented represented a $75 \%$ enrollment rate (9/12 total students).

\subsection{Data Sources}

Archival data related to the ecovillage, college, and previous EDEs were collected prior to the start of the course. These data consisted of website documents, enrollment documents, course reports, and online blogs, and were used mainly in support of our selection of the EDE as the case. Document types consisting of lesson plans, handouts, self-assessments, and student evaluation forms were also collected during the course.

Field observations were conducted by the first author using an overt-participatory methodology which is "the mode of data collection whereby a case study researcher becomes involved in the activities of the case being studied" [30] (p. 240). As such, he took part in all course activities. Descriptions of these activities (i.e., pedagogies), observations of student/faculty behaviors, and quotes were recorded in a notebook during course activities. Observational notes were only recorded for those participants who had provided IRB consent to the study. The total corpus of field transcriptions consisted of 23 separate days of observations during weeks $1-4$ of the course.

At the end of week 4, student participants were given a 103-item survey which was a modified combination of the Learning Activities Survey [35] and the Transformative Learning Survey [36]. The instrument combined demographic questions (4 items), scales (92 items), multiple-choice questions ( 3 items), and open-ended questions (4 items) that were designed to infer whether a participant experienced transformative or emancipatory learning, the outcome of that learning, and the processes by which the learning took place. The combined survey included all of the constructs of cognitive, social-emancipatory, and extra-rational learning theories, processes, and outcomes of the constituent surveys [4,37]. Accordingly, a transformative learning experience was operationalized as "an experience of significant personal change." Neither the Learning Activities Survey nor the Transformative Learning Survey are validated instruments; therefore, the surveys were primarily offered for their open-ended question (i.e., narrative) portions, whereby participants could provide written phenomenological descriptions intended to inform subsequent data collection. 
Finally, all student, faculty, and administrative study participants were interviewed using a semi-structured format. Semi-structured interviews allow for "specific questions to be asked of all respondents, but the order of questions and the wording of specific questions and subquestions follow a unique and customized conversational path with each respondent" [31] (p. 154). This interview format was chosen because it allowed for customization based on responses to survey questions. Student interview questions (22 in total) were focused on exploring their self-described experiences and outcomes of pedagogical practices that resulted in transformative or emancipatory learning. Faculty and administrator interview questions (18 in total) focused on the pedagogies, challenges, and reasons for engaging in transformative and emancipatory learning in the course. Each interview took approximately $45 \mathrm{~min}$ and was audio recorded subsequent to verbal consent. Interviews took place within \pm 4 days of the completion of the course.

\subsection{Data Analysis}

Data from the study were qualitatively analyzed using a cyclical thematic analysis strategy. This strategy incorporated the use of data organizing, memo writing, and immersive/dialogic engagement [31] (i.e., peer debriefing). Initial archival data were reviewed in order to vet the goals and research questions of the study by answering the questions "are we likely to observe transformative and emancipatory learning during the EDE?" and "will these observations correlate with a sufficiently large variety of pedagogies such that they are transferrable to higher education?" Field observations were transcribed by the researcher daily and reviewed at regular intervals in peer debriefing sessions [31] to discuss observations, organize data, and corroborate emerging themes and categories. Surveys were collected and digitally rendered prior to conducting interviews (i.e., sequential analysis), and used to inform interview sub-questions. Semi-structured interviews were initially transcribed using $\operatorname{Rev}^{\circledR}$, a professional, crowd-sourced, fee-based, transcription service. Transcriptions were proofed by the researcher during a pre-coding reading of the interview data. Field notes, surveys, and interview transcripts were all subsequently loaded into Dedoose ${ }^{\circledR}$ for coding.

Data were coded both deductively from theory and inductively from emergent patterns. Deductive coding of the data mirrored our research questions in trying to understand the outcomes and the processes of TSE as described in the broader transformative theory literature. Inductive coding, alternatively, attempted to match patterns across participants that were not already present in the literature, but that might be relevant to the practice of TSE in higher education settings. All coding was iterative and occurred in 4 steps: (1) proofing of the transcripts alongside the audio files to ensure transcript accuracy, (2) excerpting according to deductive and inductive parent themes, (3) re-organizing parent themes and assigning child codes, and (4) re-organizing child codes and accumulating evidence. Each iteration included peer debriefing [31] (i.e., dialogic engagement) and re-reading of the data. Field observations, surveys, and interview data were all coded together. A coding audit trail (i.e., codebook), which included key constructs and definitions, was maintained documenting the evolution of the coding schema.

Initial deductive coding themes originated from theoretical foundations used to formulate the research questions and were aimed at describing participants' experiences of transformative and emancipatory outcomes and processes. Thus, first-order coding reflected the outcomes and processes associated with three prevalent strands of transformative learning theory: the social emancipatory, the cognitive, and the extra-rational $[12,36,38]$. Second-order deductive categories were developed using axial coding, which "describes a category's properties and dimensions and explores how the categories and sub-categories relate to each other" [39] (pp. 235-236). As a final form of analysis and internal validity, member checking (i.e., respondent validation) of the final code schema was conducted with a subset of student and administrator participants to help reduce bias in the analysis [40]. 


\subsection{Ethical Considerations}

Partner approval for this study was granted by Findhorn Foundation College in October 2017. Participant enrollment letters were mailed to potential student, faculty, and administrative participants prior to the start of the course. All study participants gave their informed consent for inclusion before they participated in the study. The study was conducted in accordance with the Declaration of Helsinki, and the protocol was approved by the Ethics (IRB) Committee of Arizona State University on 24 September 2018 (STUDY00008875).

\section{Results}

Of the nine students, seven confirmed in their surveys that they believed they had undergone a "significant personal change." The following sections describe both the deductive and inductive themes and the categories (Table 1) resulting from our analysis of the data. Salient evidence for each theme/category is also provided. Most student participants did not speak English as their first language; however, to reduce the biasing of responses, participants are quoted verbatim regardless of grammar or spelling.

Table 1. Final Thematic/Coding Schema.

\begin{tabular}{ccc}
\hline Methodological Strategy & Theme & Category \\
\hline Deductive & Transformative Outcomes & Self-Awareness/Self-Growth \\
& & Interconnectedness \\
& & Personal Resilience \\
Worldview/Paradigm Shift & Relational \\
& Contextual \\
& Transformative Processes & Somatic/Emotional \\
& Emancipatory Outcomes & Multi-Perspectivism \\
& & More Courage/Less Fear \\
& Emancipatory Process & Acting New Knowledge/Skills \\
& Disenchantment & Relational \\
& & Realization of Social Complexity \\
& Conflict Avoidance \\
& Hindrances/Constraints & Gearning What I Already Know \\
& & Time Constraints \\
& & Intellectual Content/Skills Focus \\
\hline
\end{tabular}

\subsection{Transformative Outcomes}

\subsubsection{Self-Awareness/Self-Growth}

A common pattern across participants' descriptions of the outcomes of their transformative experiences was that of self-awareness/self-growth. As the multiple strands of transformative learning theory continue to undergo critical reflection, "the overlap between them and the fragile nature of the boundaries between them becomes apparent" [37] (p. 8). However, the strand of transformative learning theory which best aligned with the category of self-awareness and self-growth is the developmental strand. The developmental strand, supported by multiple theorists [38,41,42], elaborates transformative learning within a framework of increasing (i.e., developing) epistemological complexity—knowing ourselves and ourselves in relationship with others in ways "more responsive to the crises our species must address with new imagination" [42] (p. 147). This theme of increasingly complex forms of self-knowledge and self-awareness was commonly described. One participant explained the outcome in contrast to knowledge fulfilment: “For me, it wasn't the knowledge because the knowledge I [already] had more or less... It was more about my own inner development and self-growth." Similarly, in her survey response, the following student described her experience eloquently: 
The experience was about how to communicate and how to listen to myself. For example, the session with [guest faculty] in the first week, where we exercised to listen to body sensations, feelings and separate them from our projections and be conscious about the filter we have (assumptions, past experiences...), that gave me insights about how to get to know myself better in terms of communication and rely on me.

These types of developmental changes are essential preliminary components of TSE, where knowledge about our own habits, conditions, behaviors, and patterns in relationships with other human beings is central $[16,17]$.

\subsubsection{Interconnectedness}

A sense of interconnectedness with other humans, as well as with non-humans (sometimes referred to as "nature connection"), is tantamount to sustainable transitions [6,43]. In his own words, Selby describes the ultimate goal as "radical interconnectedness", signaling a divergence from traditional conceptualizations of human-human and human-nonhuman relations, toward a level where "entities are not primary, solid, or separate" and where "the relationship becomes primary, and the entity is itself a secondary manifestation" [44] (p. 82).

The importance of this shift was echoed by a course instructor when he described humanity's dilemma in his own words:

It's getting people not just into their body, but into the body of nature, and I think we're going [to need] to actually turn things around in the predicament that we're in, in that we actually have to actually sense and feel the natural worlds around us.

As previously mentioned, this shift is relevant not only to human relationships with non-humans, but also to human-human relationships. As one student remarked:

Now I think that there's something we have to learn, or something we have to approach or start with in the social relationships and not just do them... so I will be more observing and more trying to bring in that stuff so I have to be more aware of what's going on between humans in general.

\subsubsection{Personal Resilience}

Similarly, resilience emerged as a salient outcome of students' transformative experiences. This is a particularly useful outcome in the context of sustainability, where failure is common, and the challenges are immense. Cultivating skills and ways of being in the world that balance inner and outer wellness, compassion for others and self, and a sense of deep time are essential in sustainability and sustainability education [45]. One student in describing his growing resilience claimed:

I know there will be times in future when each of us, someday is just tired and no energy and that was one of the moments I wanted to save in my brain. ... You have a bad moment in the future and then I want to remember that moment that was a place of energy.

Another student framed her outcome around the concept of persistence and dedication to a project:

So, if for instance, if I'm working with a project, I used to leave this project as soon as I find out that this project was not that perfect that I thought it was... I think now I would think a lot about leaving something, I think I need to stay a little bit longer and look more into the beauty of the things... So I think this will give more resilience sometimes in that sense.

\subsubsection{Worldview/Paradigm Shift}

Finally, several students underwent a transformation resulting in a shift in worldview. This phenomenon is commonly described in the transformative learning literature $[12,46,47]$ and is 
consistent with Mezirow's [48] descriptions of individual perspective shifts. One notable description of this kind of shift was described by a student who explained it as a kind of awakening:

One of the biggest things is the social aspect of everything opened up to me and I was always like, not looking at it because it's like. .. we just live and it's just, we just do it, but it doesn't work like this and it's like a huge world that opened up.

This participant's opening up to a new worldview demonstrated an important step toward realizing that the sustainability issues facing humanity are more than just material issues to be solved with technocratic approaches. They are also nested within/entangled with human socio-political structures and dynamics. This underscores the importance of, as one student stated, being "invited and challenged to open up to others and really examine my values, beliefs, and behaviors."

\subsection{Transformative Processes}

Processes of transformative learning have been well described over the last several decades [12,35], leading to widely varied pedagogical strategies/approaches in a multitude of educational settings. Some scholars have attempted to codify the processes $[4,6,49]$, leading to multiple domains that are more or less applicable to the varied settings of sustainability education. Many of these processes were observed during EDE.

\subsubsection{Relational}

Relational (i.e., interpersonal, and community-based) learning was present in many student descriptions of their transformative processes. One student explained in her survey: "most influential was interacting with classmates/the group because I discovered the most about myself and [emphasis added] the other in that" and further, "the facilitators support and challenges were helpful, but not the learning itself."

The widely varied ages of students in the EDE seemed to help one student who described her process while using her own terms:

Here, there're a lot of things that I call collateral learning. A lot of collateral learning, like being in contact with intergenerational people, that's different from being in contact with your kids or grandchildren. It's different because you can more easily observe how you behave and how the others also behave. And it has helped me understanding the issues..."

In addition to generational differences, student learning was also catalyzed by needing to process relational interactions with persons having widely varied perspectives on sustainability. One student remarked:

Here in Findhorn I got very clear that. . people are very, very different, and sometimes I talk banana and you will understand this banana as orange and sometimes I talk orange and you take it as a pineapple, and how communication is important and openness too.

Relational approaches to transformative learning are building momentum recently in the context of TSE $[16,17]$ and offer avenues for revitalizing transformative learning research.

\subsubsection{Contextual}

Another significant finding regarding students' processes of transformation was the importance of context. The importance of context in processes of transformation may often be overlooked in traditional higher education settings because those settings are assumed to be ideal for learning. The rise of community-based learning [6], "real-world" learning [50], and outdoor learning [51] movements challenge this assumption. Learning for sustainability in an ecovillage context, where educational programming tends to be non-formal and highly place-specific, appears to have benefits as well, as described by one student: 
I think it was very good to be here, or to be in an ecovillage and to have examples and to have the possibility to talk to people and to have that connection, and collection of information and people. I think it makes sense rather than in the city or anywhere in any building, you know? So I think it's important.

The meaning and importance of context in the EDE was further supported by a faculty participant when she explained "it's the fact that you're living with a bunch of people... it's very intensive, so it's a kind of contextual potential for transformation." Finally, an administrator of the EDE mentioned:

People with high expectations seem to have a transformative experience where they seem to drop into something broader or deeper than content. Something around that shifts.... People who don't understand the setting of the course, and think they're walking into a straight-up center, and then when they come in and they start understanding the place, they seem to drop into a transformative experience when they open up to the setting.

\subsubsection{Somatic/Emotional}

Lastly, somatic/emotional processes in the EDE modules also led to transformative outcomes for students. These processes were often uniquely combined in experientially embodied activities that tended to take students beyond their conditioned expectations of learning:

Because it was real, kind of. Or, yeah, it was not, it wasn't in the classroom and it was outside, it was with nature, everybody, yeah, I mean. The fire and the music and it felt like life and not like learning something.

The following student also described his very emotionally transformative process that took place during a storytelling activity:

[Faculty member] led us in a journey-past-present-future. The whole present EDE group, firepit, [faculty member] and his music and story led me deep in a heightened emotional state. Vulnerability and strength simultaneously. At that time, I felt very emotionally bound to the stories shared. Connection and belonging, understanding.

\subsection{Emancipatory Outcomes}

The concept of "outcomes" in the context of emancipatory learning requires clarification, as it is often used in ways that are not emancipatory. The goal is not to prescribe outcomes, be they knowledge, skills, attitudes, values, or ontological frameworks considered important by "experts," as that would be an instrumental, not emancipatory, approach to education $[9,11]$. Rather, the goal is a willingness to engage in a co-constructive, action-oriented, discourse about desired potential futures. Emancipatory learning is about shared-meaning making as opposed to meaning receiving, and a multilogue as opposed to a monologue. Derived from the work of Freire [5], it is described as education that challenges power structures (both inside and outside the classroom) through a praxis of dialogue and action. Emancipatory learning also seeks to transgress boundaries of race, sex, and class through pedagogies of participation and shared meaning making [13]. Some scholars distinguish between learning for empowerment and emancipatory learning as leading to either personal or social change respectively [52]. Here, we combine them to mean the same concept, emancipatory learning, where, for the purpose of this study, self-empowerment is viewed as a common precursor to action for social change.

\subsubsection{Multi-Perspectivism}

Many students had experiences leading to outcomes that aligned with our conceptualization of emancipatory learning. One common theme was that of greater openness to differing or oppositional viewpoints, which we categorized as multi-perspectivism. In this category, students begin to realize 
that their worldview is not the only worldview, and that empathy and consideration are required to understand oppositional stances. This was very clearly stated by one particular student who shared: "I think one thing that I could see here very clear is how people have different mindsets and different perspectives and you know, is very different... I thought that everyone had the same mindset as myself." Another student stated her insight clearly in the context of sustainability:

I believe it will help me in my sustainability work because I now am confident, or more confident, about my ability to be "in another's shoes" or to walk their path. I believe we need this ability to successfully work with issues of sustainability at whatever level or facet that we choose.

\subsubsection{More Courage/Less Fear}

Another pattern that was common across participants' emancipatory outcomes was that of courage building. A bold willingness to act and become entangled in messy social and political systems is a prerequisite for social change. Therefore, emancipatory pedagogies are often meant to take us to our edges of discomfort. This was evident for one student who faced his fears of being judged by his classmates:

I think also one of my biggest things was fear of judgment and criticism. ... But through acceptance and belonging for a community, I think I can go through those skills and level up, gain more confidence through that.

Another student had a similarly powerful experience during another activity where she surprised herself by using her singing voice as a form of expression. When asked how the experience would change how she approached her education-related work, she responded:

I think I might be much more light, and I'm always trying to bring fun to my classes. I try hard to do that, because humor I think can be flashpoints people remember because there was a humorous event. But I think it's going to bring more play... I feel like I can do anything. I sang! In public!

\subsubsection{Acting on New Knowledge/Skills}

Finally, acting on or with newly obtained knowledge and skills was a pattern across participants with regard to emancipatory learning. One student explained "I feel like there's a lot of information and if I need it, I can always go there." Another student who was starting a business back home described: "I would love to bring this knowledge back to Latvia together with environmental education. Through this event [his learning experience] and EDE I gather motivation and strength to continue being a pioneer!" These, and other examples explaining new knowledge or a willingness to use new skills were further elucidated by the administrator who explained:

The EDE program is a platform to support students, and I think this is of many EDEs, is a platform to support students to test their skill level and evaluate where they need to skill up, especially for those people who want to be consultants of sustainability or want to be educators in sustainability or build communities. It's almost like a self audit on what they know, what they don't know, what their fears are, [and] fears aren't.

\subsection{Emancipatory Process}

\subsubsection{Relational}

In this study, relational processes also frequently led to emancipatory outcomes for EDE students. One student felt supported to step beyond his comfort zone through community relationships of trust. He explained: 
One of the things is that I trusted in that environment. . I think only in a group you can really trust, you can go that deep and still find it enjoyable, unfortunately. But yeah, it was nice. I think I felt like in a community.

At other times, challenging relationships and power struggles led to emancipatory learning for students. After being confronted in class by a peer about her perspective, one student reflected on the anger she felt:

It was painful. . . but I somehow connected to the [colonial history of my country], and [the colonizers] was telling the indigenous people that what they were doing was everything wrong. And then they were trying them to accept their god. You know, like their church was very like, no, you have to believe in this god. Those other gods, those other things that you do, they're all wrong. So I could really feel this imperialism somehow.

A faculty member also mirrored this tendency for relational pedagogies to elicit emancipatory outcomes. In her interview, she explained connection in the following way:

There's a part that's like it kind of almost doesn't matter what's delivered in the room, it's more about. . the interweaving of people, and creating the space for them to have the conversation. So all the dyads and triads and mixing of group and opportunity for talking with other people. ... that's the ingredients, and then it's kind of like... I've got the power to actually go do something.

\subsection{Disenchantment}

The inductive theme of disenchantment is not surprising given the intractable nature of the issues that sustainability education attempts to address. Students often approach sustainability via a myriad of conceptualizations, often gleaned through social, non-formal, and even formal (but outdated) learning spheres. For example, Jickling and Sterling, make light of the fact that sustainability is still used to describe any sort of provocative activity: "sustainable mining, sustainable tourism, sustainable consumerism, and even sustainable over-fishing" [53] (p. 2). This theme is perhaps not surprising then, given the diversity of conceptualizations of sustainability students are often exposed to prior to any formal or informal sustainability education.

\subsubsection{Realization of Social Complexity}

Most often, students approach sustainability with a materialist or anthropocentric worldview that advocates for technocratic solutions. Living in an ecovillage that utilizes modern technology at the community scale (solar, wind, and bio energy; ecological buildings, hybrid carshare, regenerative water treatment, etc.), but realizing that it still faced socio-political challenges related to sustainability seemed to erode the fantasies students might have had prior to arriving. This was a very common theme in the data - the realization of social complexity. One student explained:

I think it was a pretty romantic imagination place and it's not, so. ... I thought it's like, everybody has its role and everything's clear, who's doing what, and who's responsible for what, and if there's a problem, there's a system to solve it.

Another student of the EDE who had been living in the community for a longer period reflected on her own journey:

I think the idealist in me has met some restrictions. .. after being here for eight months and seeing how a community works... how slow the development can go, or how much frustrations it can be and how fragmented it is, how difficult it is for people to live together.

The realization that social systems and their material and symbolic structures (i.e., culture) are implicated in sustainability and that they are inherently complex left an imprint on one student's 
experience of emancipatory learning. She explained in her survey that "Talks to a young woman living here made me realise that life here is also about power, old/young, male/female, living here for a long time/newcomers, etc."

\subsubsection{Conflict Avoidance}

Equally disenchanting was the tendency of students and faculty to avoid conflict when it could be potentially messy, embarrassing, or controversial. After realizing the complexity of the social aspects of sustainable ecovillage life, one student commented:

I wish there were more honesty in their failures. I feel like failure is a really powerful learning tool, and if they can acknowledge their failure and speak to it, then they can help the people coming here avoid the traps that they've made. ... Let's [also] talk about what doesn't work. There's learning to be had there.

In recognizing the difficulty of navigating contested viewpoints successfully, one participant acknowledged the need, but also the challenge, when she said:

I think what's needed at the helm of such a ship is somebody who's worked with a lot of conflict resolution stuff and has several methods available that they can do this, and not just patient listening and then, let's get to the next thing, and then the next thing, and the next thing.

\subsubsection{Learning What I Already Know}

Finally, both administrators and students noted a common form of disenchantment when they realize that the curriculum often focuses on information or skills that they have learned already. In an age of overabundant and readily available information, this is a common theme in many types of education. One administrator commented on the phenomenon in a positive way by saying:

Those people who come here and get pretty pissed by what isn't here, and what isn't available, and what the curriculum isn't, find out learning what they already know and what they're super passionate about and what they stand for. ... I also think it's really important for people in the world to go through processes where they actually can see how much they know and how they can influence and develop.

A student reflected: "what I guess I learned during the course is that I could probably be even more sure about what I'm into and what I'm not." These examples, combined with the tendency toward conflict avoidance, suggest just how challenging truly transformative and emancipatory sustainability education is regardless of the setting, and how easy it is to fall into traps of delivering information-based learning that is already easily accessible via other sources, and too often repeated.

\subsection{Hindrances/Constraints}

\subsubsection{Global North Bias}

As students progressed through the EDE program, they began to meet hindrances and or constraints that they often expressed through their survey and interview data. One such hindrance that is also very likely to exist in many North American and European IHLs is that of the Global North bias. Often, the issue is not the existence of a bias, but rather our blindness to it. As one student explained in her interview:

The first thing that I would change about the course is to have more of the worldview dimension because I think... for me is one of the most important things. So, and also about the relationship between global north, global south, this kind of different perspectives, you know... I think this was blank because it's still westerns bringing the perspective. 
Another student similarly expressed, "I think instead it was very much about taking the principles of the modern world into a course." These limitations may not have been intentional; however, one faculty member was cognizant of the issue in trying to introduce non-Western perspectives. He mentioned in his interview:

I don't want to idealize indigenous peoples, but I've learned a lot from indigenous people in that most of them in their true sense, they see the earth as sacred, and they see everything as having a right to exist. They see that there's something to be learned from... a rock or a tree, and they become allies, and so... it's this big classroom, and basically it seems to be free.

\subsubsection{Time Constraints}

Another theme that was prevalent in the data that is also very common in higher education settings was the time constraint. Here, students themselves often recognized that loyalty to a schedule can compromise learning. One student commented that "the things that I knew something about before I understood better and the things that I haven't had words on early on, I really felt there was too little time to really get an understanding." A faculty member also realized the dilemma and stated in her interview:

I think I'm still learning how to do it. . . one of the unique challenges is time, because if you stand and do transmissive... you can cover a lot more ground. But is anyone actually learning anything?... So if you want to do something that's more participatory, you've gotta say less is more.

\subsubsection{Content Focus}

The previous two constraints (Western bias and time) often lead to another hindrance evident in this study-the tendency to over-focus on intellectual content and skills and ignore embodied learning. This is very common in IHLs where content-related outcomes determine educational success. However, this theme was also evident in the EDE, where conditioning to information delivery may be strongly habituated. Here, many students expressed the desire for less intellectual information and more embodied learning. For example, one student who did not have a transformative or emancipatory learning experience claimed: "I think a lot of these principles that we were given a lip service, but they were not embodied experiences." Another stated the need for "more practical [learning]. . . to learn more through your body and not through your mind." Finally, a student who struggled with boredom explained: "There's things that I found so boring, or so kind of [pauses], nothing is happening in my body when we do this." These are common challenges in any education setting but are more important to resolve in the context of TSE, where holistic learning is deemed essential $[6,54]$.

\section{Discussion}

The goals of this study were, firstly, to determine the extent to which an exemplary case of sustainability education outside of the traditional IHL could be transformative/emancipatory for learners and, secondly, to provide a rich description of the curriculum such that its pedagogical elements might be applied to TSE in IHLs. Overall, the EDE course conformed with our conceptualization of TSE, in that it led to outcomes that were either transformative or emancipatory for most students and utilized innovative pedagogies intended to be restorative and/or integrative [55]. While our analysis provided resultant categories of transformative and emancipatory learning that were often linked to multiple elements of the curriculum, here we elaborate on three unique pedagogical elements that were particularly potent catalysts leading to transformative and emancipatory outcomes. Finally, we summarize the potential learning constraints and hindrances to utilizing these types of pedagogies for TSE within IHLs. 


\subsection{Ritual Pedagogies}

Rituals as transformative pedagogies are an ancient practice [56,57]. While the term "ritual" has been debated by anthropologists for decades [58], here we use a working definition of ritual as a formalized, symbolic performance. Rituals have a distinct beginning, ending, leader, and spatial context (e.g., this earth lodge, this sanctuary, this meadow, etc.). Further, because they are performative, participants' bodily movements, sensations, mien, and posture are all central elements and more important than any accompanying narrative. Accordingly, ritual pedagogies incorporate the relational, contextual, and somatic/emotional elements of TSE described in our analysis.

For millennia, premodern cultures have used ritual pedagogies for learning how to live sustainably [59]. Only relatively recently has Western civilization almost ceased to use them in the context of education [57,60], opting instead for what Moore [56] refers to as pseudo-rituals. They are described as "pseudo" because they often lack integration, which can leave learners with a sense of incompleteness. Examples of pseudo-rituals include graduations, parties, proms, etc.

In descriptions of what led to their transformative and emancipatory outcomes, many EDE participants referred to activities that are consistent with our working definition of a ritual. Indeed, the EDE faculty utilized many types of rituals including blindfolded nature walks, building of labyrinths, and outdoor ceremonies. One notable example in which the class participated was a ritual that took place at night, during full moon, in an earth lodge sanctuary. Beginning in silent darkness, participants were invited to quietly center themselves. A fire was lit, and a poetic narrative was recited regarding the genesis and evolution of the cosmos-and humanity's place within it. The facilitator then played various instruments, inviting participants into a meditative state. Finally, participants were asked, in turns, to speak about their own life within the context of this larger universal story. The activity was a potent pedagogy because it engaged several transformative processes: relationality, context, and soma/emotions. The activity also incorporated many contemplative pedagogical elements including centering, meditation, visualization, music and singing, council, deep listening, and storytelling. Contemplative pedagogical approaches are deemed important in future innovations of TSE $[4,54]$ and this mixture of elements had a profound effect on several students. One noted:

It also touched some origin feeling you know, like this tribe feeling or it was not just a good experience and fun, it was really like coming down and really connecting but not only with the people but with the place and with life.

Even a student whose survey indicated he did not undergo a transformative experience during the EDE mentioned:

[It] was a really, really, powerful experience, and that doesn't really conform to any of the models that I would've had in my mind arriving here as a session, like just gathering in an earth lodge and having a talking stick and taking turns sharing whatever you're moved to say and put into the space, whether that's a poem or a song or a thought. It was really powerful.

Such descriptions provide insight into the powerfully transformative potential of ritual pedagogies that are hallmarks of premodern forms of education, and which are still common features in ecovillage education today.

\subsection{Pedagogies of Story}

Today, the practice of storytelling is as important as it has ever been [61-63]. Much like contemplative rituals, storytelling is also a contemplative pedagogy [4], and has been around for millennia as an essential tool for the sustainability of cultures with strong oral traditions. However, its application to modern sustainability and sustainability education has only more recently begun to draw attention [61-63]. For example, Veland et al. argue that we should not underestimate stories, as they essentially "constrain and enable what is thinkable and sayable about the past, present, and future" [62] (p. 42). Further, as Cron articulates, humans are essentially wired for stories: "we think 
in stories, and this allows us to envision [and create] a future" [64] (p. 6). Thus, stories and storytelling are incredibly powerful pedagogies that allow us to connect and envision desirable pathways toward sustainable futures.

Storytelling was another potent pedagogy for TSE in this study, weaving together many of the resultant categories of transformative and emancipatory learning processes found in our analysis. Storytelling was inherently relational, contextualized, and emotional (when told well). It also required students to be good listeners and aware of more than just their words. Finally, the use of story was also performative, requiring an actor and an audience.

The EDE utilized many storytelling pedagogies during the length of the course. Many were intended to build trust, interpersonal connection, and multi-perspectivism through personal interaction. A noteworthy example of a storytelling pedagogy used during the fourth week of the course was an exercise called "council of beings." With elements similar to the earth lodge ritual, this activity began with a silent nature walk where students were encouraged to find a non-human "ally" and communicate with that ally, allowing it to share its wisdom and communicate its desires for humanity. Afterward, we convened indoors to create masks (representing our ally) that would be worn during a final council gathering. Upon entering the council gathering, each student put on their mask and "became" their ally being. The act of telling story from the perspective of the ally was also an important aspect of the activity. A student explained how this particular element empowered her:

It was the mask. That I had something to hide behind, even though everyone knew who was behind the mask. And it's kind of a metaphor. I wear a mask, but I put on a mask to let myself out.

Thus, storytelling can be a powerfully transformative and emancipatory pedagogy for TSE. According to Cron [64], we are made to hear and to tell stories. As she describes, "the brain uses stories to simulate how we might navigate difficult situations in the future" [64] (p. 166). This makes them particularly suitable to sustainability education, where contemplating and navigating uncertain futures is a central theme.

\subsection{Collaborative Pedagogies}

Recently, scholars from multiple fields have begun to view sustainability, and therefore sustainability education, through relational ontological frameworks. For example, Morton [65] argues for a shift from humanity with a sense of "omnipresence, omniscience, and omnipotence" to humankind embedded in the "symbiotic real" (p. 2). He defines the symbiotic real as a mutual "reliance between discrete yet deeply interrelated beings" immersed in a phenomenology of "solidarity" (p. 2). Similarly, both Lange [16] and O'Neil [17], draw from Barad's [66] work with agential realism to articulate ontologies of relationality where human-human and human-non-human interactions are inseparable. Within these frameworks, agency emerges through a performance of intra-actors, and all beingness is collaborative.

The categories resulting from our analysis suggested patterns consistent with these emerging relational frameworks for TSE. Outcomes of connection, emerging through interpersonal processes embedded in a community of actors, were frequently described by EDE students who were encouraged to value others' worldviews and perspectives alongside their own, but who were also at times supported and encouraged by their peers to explore their safety zones and find their source of personal power and resilience. These kinds of outcomes were similarly described by EDE faculty and administrators who recognized that practicing skills for better collaboration is tantamount to TSE.

Collaborative pedagogies were integrated into the course through group design projects that began in week two and lasted until the final week. The goal of the project was to design a development project for an ecovillage. The project was unique in that, unlike participatory learning that often occurs in IHLs, groups designed and approved their own working agreements. For example, at the end of every week, each group held a retrospective meeting, where group members held council about what 
was and was not working in the group process and assessed whether new agreements were needed, or existing ones required modification. Thus, during the EDE, emphasis was frequently placed on the process of collaboration, as opposed to the outcome of collaboration. Another unique element of the course was that collaboration was conceptualized as a more-than-human process. In other words, group participants were encouraged to think of ways in which they could collaborate with non-human beings in their projects, thus embodying relational ontologies beyond anthropocentrism. While the planet currently houses seven billion human inhabitants, it is also home to billions of other beings. Pedagogies that focus on the processes rather than only the outcomes of collaboration help develop the skills required for a sustainable and just existence within the symbiotic real.

\subsection{Where to Now? —Conclusions, Constraints, and Cautionary Tales}

Seeking examples of exemplary cases is a common strategy in applied sustainability, where researchers often articulate pathways of transformation by triangulating theory, practice, and real-world examples [30,67]. Further, this approach acknowledges that IHLs do not have all the answers to society's problems, and that innovative approaches can often be found in settings that are more accustomed to social experimentation. Since enacting pedagogies of ritual, story, and collaboration might challenge the norms of contemporary IHLs, pedagogical laboratories like Findhorn College are needed in an evolving field and should continue to be explored for innovation.

While we do not advocate tossing out familiar curricula and pedagogies, we encourage facilitators to explore the edges of their comfort zones through the use of pedagogies of ritual, story, and collaboration. In our study, ritual pedagogies engaged participants in ways that were deeply embodied and experiential, awakening their senses and leading them toward, and occasionally beyond, their worldview boundaries. Pedagogies of story drew learners into deep listening spaces using richly contextualized narratives that engaged their emotions and used metaphor as a way to explore their hopes, fears, and visions for the future. Finally, collaborative pedagogies brought participants together in ways that forced them to acknowledge and work with different and potentially oppositional worldviews-essential skills on a planet headed toward a population of 10 billion human inhabitants. Therefore, we encourage facilitators to explore these approaches in initially smaller and more balanced doses, allowing learners to acclimate to curricular and pedagogical changes that, at first, may seem overwhelmingly unfamiliar.

We also caution facilitators willing to try these approaches that, when removed from their original (i.e., ecovillage) context, these methods should be re-assessed for their relevance, appropriateness, and applicability. For example, time constraints and over-emphasis on knowledge and skill outcomes emerged in our analysis of learners' experiences of the EDE. These constraints are even more intense in IHLs, where skill- and knowledge-orientation drives a broadly vocationalized education focused on labor provision [14,15]. Students' experiences in IHLs also tend to be more fragmented, the result of widely varied coursework and overloaded schedules. True TSE is difficult, if not impossible, to measure and assess. Therefore, such approaches are bound to clash with curricula focused on measurable skill and knowledge outcomes that conform to predetermined standards. Emancipatory pedagogies can be even more challenging because they encourage entanglement with power structures. As hooks [13] suggested, we must be prepared for antagonism and be willing to dissent from norms. She also reminds us just how "deep seated is the fear is that any decentering of Western civilization... is really an act of cultural genocide" (p. 32).

Nevertheless, rituals, stories, and collaborative action are transformative and liberating practices important for TSE. However, they can be used in other ways too. For example, the proliferation of authoritarian and dystopian storylines is frequently found in modern cinema [62] and rituals can also be used to dismantle desirable pathways of change [68]. Thus, in implementing innovative pedagogies in TSE, we should proceed with care. Powerful pedagogies for change should lead us to an increasing diversity of ideas that foster creativity. They should resist standard setting that instrumentalizes education and encourage standard seeking that creates space for new thoughts, values, and pathways 
of development [9]. In doing so, IHLs can contribute to the goal of generating, rather than prescribing, future possibilities, and play their increasingly important role in transitioning humanity toward a just and sustainable future.

Author Contributions: Conceptualization, J.P. and E.M.; Data curation, J.P. and E.M.; Formal analysis, J.P. and E.M.; Funding acquisition, J.P.; Investigation, J.P. and E.M.; Methodology, J.P. and E.M.; Supervision, E.M.; Writing —original draft, J.P.; Writing—-review and editing, J.P. and E.M.

Funding: Travel for this research was partially funded through the School of Sustainability Martinson Grant and the School of Sustainability Culminating Experience Grant.

Acknowledgments: We gratefully acknowledge the Findhorn Foundation College for its kind support of our research in transformative sustainability education.

Conflicts of Interest: The authors declare no conflict of interest.

\section{References}

1. Capra, F. The Web of Life: A New Scientific Understanding of Living Systems; Anchor Books: New York, NY, USA, 1997; ISBN 978-0-385-47676-8.

2. Schultz, J.; Brand, F.; Kopfmuller, J.; Ott, K. Building a theory of sustainable development': Two salient conceptions within the German discourse. Int. J. Environ. Sustain. Dev. 2008, 7, 465-482. [CrossRef]

3. Wals, A.E.J.; Corcoran, P.B. The promise of sustainability in higher education: An introduction. In Higher Education and the Challenge of Sustainability; Corcoran, P.B., Wals, A.E.J., Eds.; Kluwer Academic: Dordrecth, The Netherlands, 2004; pp. 91-95.

4. Papenfuss, J.; Merritt, E.; Manuel-Navarrete, D.; Cloutier, S.; Eckard, B. Interacting pedagogies: A review and framework for sustainability education. J. Sustain. Educ. 2019, 20, 1-19.

5. Freire, P. Pedagogy of the Oppressed: 30th Anniversary Edition; Bloomsbury Academic: New York, NY, USA, 2012.

6. Sipos, Y.; Battisti, B.; Grimm, K. Achieving transformative sustainability learning: Engaging head, hands and heart. Int. J. Sustain. High. Educ. 2008, 9, 68-86. [CrossRef]

7. Sterling, S. Transformative learning and sustainability: Sketching the conceptual ground. Learn. Teach. High. Educ. 2011, 5, 17-33.

8. Issues and Trends in Education for Sustainable Development; Leicht, A.; Heiss, J.; Byun, W.J. (Eds.) UNESCO Publishing: Paris, France, 2018; Volume 5, ISBN 978-92-3-100244-1.

9. Wals, A.E.J.; Jickling, B. "Sustainability" in higher education: From doublethink and newspeak to critical thinking and meaningful learning. High. Educ. Policy 2002, 15, 121-131. [CrossRef]

10. Vare, P.; Scott, W. Learning for a Change: Exploring the Relationship Between Education and Sustainable Development. J. Educ. Sustain. Dev. 2007, 1, 191-198. [CrossRef]

11. Wals, A.E.J.; Geerling-Eijff, F.; Hubeek, F.; van der Kroon, S.; Vader, J. All mixed up? Instrumental and emancipatory learning toward a more sustainable world: Considerations for EE policymakers. Appl. Environ. Educ. Commun. 2008, 7, 55-65. [CrossRef]

12. Taylor, E.W.; Cranton, P. (Eds.) The Handbook of Transformative Learning: Theory, Research, and Practice; John Wiley \& Sons: San Francisco, CA, USA, 2012; ISBN 1118218930.

13. hooks, b. Teaching to Transgress; Routledge: New York, NY, USA, 1994.

14. Sterling, S. Assuming the future: Repurposing education in a volatile age. In Post-Sustainability and Environmental Education; Jickling, B., Sterling, S., Eds.; Springer: Cham, Switzerland, 2017; pp. 31-45.

15. Sterling, S.; Dawson, J.; Warwick, P. Transforming sustainability education at the creative edge of the mainstream: A case study of Schumacher College. J. Transform. Educ. 2018, 16, 323-343. [CrossRef]

16. Lange, E.A. Transforming transformative education through ontologies of relationality. J. Transform. Educ. 2018, 16, 280-301. [CrossRef]

17. O'Neil, J.K. Transformative sustainability learning within a material-discursive ontology. J. Transform. Educ. 2018, 16, 365-387. [CrossRef]

18. Trainer, T. The global ecovillage movement: The simpler way for a sustainable society. Soc. Altern. 2000, 19, $19-24$.

19. Van Schyndel Kasper, D. Redefining community in the ecovillage. Hum. Ecol. Rev. 2008, 15, 12-24. 
20. East, M. Current thinking on sustainable human habitat: The Findhorn ecovillage case. Ecocycles 2018, 4, 68-72. [CrossRef]

21. Accioly Dias, M.; Loureiro, C.F.B.; Chevitarese, L.; Souza, C.D.M.E. The meaning and relevance of ecovillages for the construction of sustainable societal alternatives. Ambient. Soc. 2017, 20,79-96. [CrossRef]

22. Hong, S.; Vicdan, H. Re-imagining the utopian: Transformation of a sustainable lifestyle in ecovillages. J. Bus. Res. 2016, 69, 120-136. [CrossRef]

23. Litfin, K. Reinventing the future: The global ecovillage movement as a holistic knowledge community. In Environmental Governance: Power and Knowledge in a Local-Global World; Kutting, G., Lipschutz, K., Eds.; Routledge: New York, NY, USA, 2012; pp. 138-156, ISBN 978-0-415-77712-4.

24. Burns, H.L. Transformative sustainability pedagogy: Learning from ecological systems and Indigenous wisdom. J. Transform. Educ. 2015, 133, 259-276. [CrossRef]

25. Frisk, E.; Larson, K. Educating for sustainability: Competencies \& practices for transformative action. J. Sustain. Educ. 2011, 2, 1-20.

26. Greenberg, M. What on Earth Is Sustainable?: Toward critical sustainability studies. Boom J. Calif. 2013, 3, 54-66. [CrossRef]

27. UNESCO. United Nations Decade of Education for Sustainable Development (2005-2014): International Implementation Scheme; UNESCO: Paris, France, 2005.

28. Wals, A.E.J. Shaping the Education of Tomorrow: 2012 Full-Length Report on the UN Decade of Education for Sustainable Development; UNESCO: Paris, France, 2012.

29. Gaia Education. Ecovillage Design Education: A Four-Week Comprehensive Course in the Fundamentals of Sustainability Design, Version 5; Gaia Education: Forres, Scotland, 2012.

30. Yin, R.K. Case Study Research and Applications: Design and Methods, 5th ed.; Sage Publications: Los Angeles, CA, USA, 2017; ISBN 1506336159.

31. Ravitch, S.M.; Carl, N.M. Qualitative Research: Bridging the Conceptual, Theoretical, and Methodological; Sage Publications: Thousand Oaks, CA, USA, 2016; ISBN 9781483351742.

32. Findhorn College. About Our Approach. Available online: https://www.findhorncollege.org/about/aboutour-approach/ (accessed on 13 March 2019).

33. Boyd, R.D. Personal Transformations in Small Groups: A Jungian Perspective; Routledge: New York, NY, USA, 2003; ISBN 1134950713.

34. Daloz, L.A. Common Fire: Leading Lives of Commitment in a Complex World; Beacon Press: Boston, MA, USA, 2015; ISBN 0807020087.

35. King, K.P. The Handbook of the Evolving Research of Transformative Learning: Based on the Learning Activities Survey; IAP: Charlotte, NC, USA, 2009; ISBN 1607522020.

36. Stuckey, H.L.; Taylor, E.W.; Cranton, P. Developing a Survey of Transformative Learning Outcomes and Processes Based on Theoretical Principles. J. Transform. Educ. 2013, 11, 211-228. [CrossRef]

37. Cranton, P.; Taylor, E.W. Transformative learning theory: Seeking a more unified theory. In The Handbook of Transformative Learning: Theory, Research, and Practice; Taylor, E.W., Cranton, P., Eds.; Jossey-Bass: San Francisco, CA, USA, 2012; pp. 3-20.

38. Dirkx, J.M. Transformative learning theory in the practice of adult education: An overview. PAACE J. Lifelong Learn. 1998, 7, 1-14.

39. Saldaña, J. The Coding Manual for Qualitative Researchers; Sage Publications: Thousand Oaks, CA, USA, 2016.

40. Maxwell, J.A. Qualitative Research Design: An Interactive Approach; Sage Publications: Thousand Oaks, CA, USA, 2013.

41. Kegan, R. What "form" transforms? A constructive-developmental approach to transformative learning. In Learning as Transformation: Critical Perspectives on a Theory in Progress; Mezirow, J., Ed.; Jossey-Bass: San Francisco, CA, USA, 2000; pp. 35-70.

42. Taylor, K.; Elias, D. Transformative learning: A developmental perspective. In The Handbook of Transformative Learning: Theory, Research, and Practice; Taylor, E.W., Cranton, P., Eds.; Jossey-Bass: San Francisco, CA, USA, 2012; pp. 3-20.

43. Nolet, V. Educating for Sustainability: Principles and Practices for Teachers; Routledge: New York, NY, USA, 2016.

44. Selby, D. The signature of the whole: Radical interconnectedness and its implications for global and environmental education. In Expanding the Boundaries of Transformative Learning: Essays on Theory and Praxis; O'Sullivan, E., Morrell, A., O'Connor, M., Eds.; Palgrave Macmillan: New York, NY, USA, 2002; pp. xv-xx. 
45. De Angelis, R. Entwining a conceptual framework: Transformative, Buddhist and Indigenous-community learning. J. Transform. Educ. 2018, 16, 176-196. [CrossRef]

46. Taylor, E.W. Transformative Learning Theory-An Overview. In The Theory and Practice of Transformative Learning: A Critical Review. Information Series No. 374; ERIC: Columbus, OH, USA, 1998; pp. 5-20.

47. Kitchenham, A. The Evolution of John Mezirow' s Transformative Learning Theory. J. Transform. Educ. 2008, 6, 104-123. [CrossRef]

48. Mezirow, J. Education for Perspective Transformation: Women's Re-Entry Programs in Community Colleges; Columbia University Teachers College: New York, NY, USA, 1978.

49. Kasworm, C.E.; Bowles, T.A. Fostering transformative learning in higher education settings. In The Handbook of Transformative Learning: Theory, Research, and Practice; Taylor, E.W., Cranton, P., Eds.; Jossey-Bass: San Francisco, CA, USA, 2012; pp. 388-407.

50. Brundiers, K.; Wiek, A. Educating Students in Real-world Sustainability Research: Vision and Implementation. Innov. High. Educ. 2011, 36, 107-124. [CrossRef]

51. Lugg, A. Developing sustainability-literate citizens through outdoor learning: Possibilities for outdoor education in higher education. J. Adventure Educ. Outdoor Learn. 2007, 7, 97-112. [CrossRef]

52. Inglis, T. Empowerment and emancipation. Adult Educ. Q. 1997, 48, 3-18. [CrossRef]

53. Jickling, B.; Sterling, S. Post-sustainability and environmental education: Framing issues. In Post-Sustainability and Environmental Education: Remaking Education for the Future; Jickling, B., Sterling, S., Eds.; Springer Nature: Cham, Switzerland, 2017; pp. 1-11.

54. Contemplative Approaches to Sustainability in Higher Education: Theory and Practice; Eaton, M.; Hughes, H.J.; Macgregor, J. (Eds.) Routledge: New York, NY, USA, 2017; ISBN 978-1-138-19018-4.

55. Lange, E.A. Transformative and restorative learning: A vital dialectic for sustainable societies. Adult Educ. $Q$. 2004, 54, 121-139. [CrossRef]

56. Moore, R.L. The Archetype of Initiation: Sacred Space, Ritual Process, and Personal Transformation; Xlibris Corporation: Bloomington, IN, USA, 2001.

57. Turner, V. The Ritual Process: Structure and Anti-Structure; Routledge: New York, NY, USA, 1995.

58. Quantz, R.A. School ritual as performance: A reconstruction of Durkheim's and Turner's uses of ritual. Educ. Theory 1999, 49, 493-513. [CrossRef]

59. Cajete, G. Native Science: Natural Laws of Interdependence; Clear Light Publishers: Santa Fe, NM, USA, 2000.

60. Moore, R.L.; Gillette, D. King, Warrior, Magician, Lover; HarperCollins: San Francisco, CA, USA, 1991.

61. Haven, K. Story Proof: The Science Behind the Startling Power of Story; Greenwood Publishing: Westport, CT, USA, 2007.

62. Veland, S.; Scoville-Simonds, M.; Gram-Hanssen, I.; Schorre, A.K.; El Khoury, A.; Nordbø, M.J.; Lynch, A.H.; Hochachka, G.; Bjørkan, M. Narrative matters for sustainability: The transformative role of storytelling in realizing $1.5^{\circ} \mathrm{C}$ futures. Curr. Opin. Environ. Sustain. 2017, 31, 41-47. [CrossRef]

63. Leinaweaver, J. Storytelling for Sustainability: Deepening the Case for Change; Routledge: New York, NY, USA, 2015.

64. Cron, L. The Writer's Guide to Using Brain Science to Hook Readers from the Very First Sentence; Crown Publishing: New York, NY, USA, 2012.

65. Morton, T. Humankind: Solidarity with Non-Human People; Verso Books: Brooklyn, NY, USA, 2017.

66. Barad, K. Meeting the Universe Halfway: Quantum Physics and the Entanglement of Matter and Meaning; Duke University Press: Durham, NC, USA, 2007.

67. Brundiers, K.; Wiek, A.; Redman, C.L. Real-world learning opportunities in sustainability: From classroom into the real world. Int. J. Sustain. High. Educ. 2010, 11, 308-324. [CrossRef]

68. Collins, S.T. Communitas, ritual, and sustainability in Peter Senge's presence: Human purpose and the field of the future. Bull. Sci. Technol. Soc. 2005, 25, 491-496. [CrossRef]

(C) 2019 by the authors. Licensee MDPI, Basel, Switzerland. This article is an open access article distributed under the terms and conditions of the Creative Commons Attribution (CC BY) license (http://creativecommons.org/licenses/by/4.0/). 